Hydrology and Earth System Sciences, 8(6), 1051-1064 (2004) C EGU

\title{
Application of time-series analyses to the hydrological functioning of an Alpine karstic system: the case of Bange-L'Eau-Morte
}

\author{
Thibault Mathevet, ${ }^{1}$ Michel Lepiller ${ }^{2}$ and Alain Mangin ${ }^{3}$ \\ ${ }^{1}$ Cemagref - Parc de Tourvoie, BP 44 - 92163 Antony Cedex, France \\ ${ }^{2}$ Laboratoire d'hydrogéologie - EPO (Ecole Polytechnique de l'Université d'Orléans, Polytech'Orléans) - ISTO (Institut des Sciences de la Terre d'Orléans), 8 rue Léonard \\ de Vinci - 45072 Orléans Cedex 2, France \\ ${ }^{3}$ Laboratoire d'écologie des hydrosystèmes, plateforme technique de Moulis, 09200 Moulis, France
}

E-mail for corresponding author: thibault.mathevet@cemagref.fr

\begin{abstract}
This paper analyses the hydrological functioning of the Bange-L'Eau-Morte karstic system using classical and original techniques, recession curves, correlation and spectral analyses, noise analysis and wavelet analyses. The main characteristics that can be deduced are the recession coefficients, the dynamic volume of storage, the response time of the system, the quickflow and baseflow components and the snowmelt characteristics. The non-stationary and timescale-dependent behaviour of the system is studied and particular features of the runoff are shown. The step-by-step use of these different techniques provides a general methodology applicable to different karstic systems to provide quantifiable and objective criteria for differentiation and comparison of karstic systems.
\end{abstract}

Keywords: karstic hydrology, Bauges mountains, recession curves, correlation and spectral analysis, wavelet analysis, snowmelt

\section{Introduction}

Classically, the characterisation of aquifers is based on knowledge of internal parameters, permeability, transmissivity and geometry, and their boundary conditions (Mangin, 1994). Unfortunately, the mechanisms of genesis and development of karstic systems (karstification) lead to a highly discontinuous and heterogeneous medium, not only in its spatial structure but also in its temporal functioning (Mangin, 1975; Labat et al., 2000). Various degrees of karstified limestones are often found on these kinds of catchments, with highly transmissive conduits and poorly transmissive blocks. When observations and pumping or tracer tests are possible, their interpretations are limited because of the limited scale of investigation of these methods.

It has been shown, however, that preliminary studies based on time-series analysis techniques can be performed to get a basic understanding of the functioning of the karstic system. Walliser (1977) defined karstic systems as black boxes, the functioning of which could be studied through input (rainfall, temperature, etc.)-output (runoff, tracers, etc.) relationships. The present study is based on time-series analysis, from classical to more detailed techniques. The simple cross-correlation and spectral analyses often applied in karstic hydrology (Mangin, 1981, 1984) provide only a general analysis of the functioning of karstic systems. Simple correlation analysis characterises the individual structure of the time-series and its linear dependency over a time period. Simple spectral analysis is complementary to the correlation analysis and characterises the periodical phenomena of the time-series. Cross-correlation analysis characterises the link between the input and the output timeseries. Cross-spectral analysis indicates how the input is modified by the system. However, a standard Fourier transformation cannot retain the location of a particular event in time and does not perform well on irregularly spaced events or non-stationary signals. Wavelet analysis is a timedependent spectral analysis that decomposes a data series 
in the time-frequency space. Because of non-stationary and intermittent time structures in the spring outflow, wavelet analyses are used here to give a more detailed interpretation of non-stationary processes, i.e. to give a timescale representation of these processes and their relationships (Nakken, 1999; Labat, 2000; Lafrenière and Sharp, 2003).

This paper presents the functioning of the Bange-L'EauMorte karstic system (BLMKS), a small karstic system monitored since the 1970s (Lepiller, 1976, 1980, 1982), with a homogeneous geological structure, located in the Bauges mountains, a French sub-alpine massif. The hydrological and geochemical signals from the different parts of the system, in particular from the non-saturated zone, are very clear. Moreover, its recharge is characterised by different processes of infiltration during the hydrological cycle. For these reasons, this system is appropriate for a detailed study of the hydrodynamical and geochemical processes in karstic catchments (Mathevet, 2002).

The paper overviews the results of different techniques of time-series analyses, developed and applied separately; it aims to provide a better understanding of karstic system functioning as well as a step-by-step methodology for a progressive study of karstic systems.

\section{STUDY AREA}

Lepiller (1980) details the geology of the area studied in the southern part of Semnoz mountain, in the Bauges

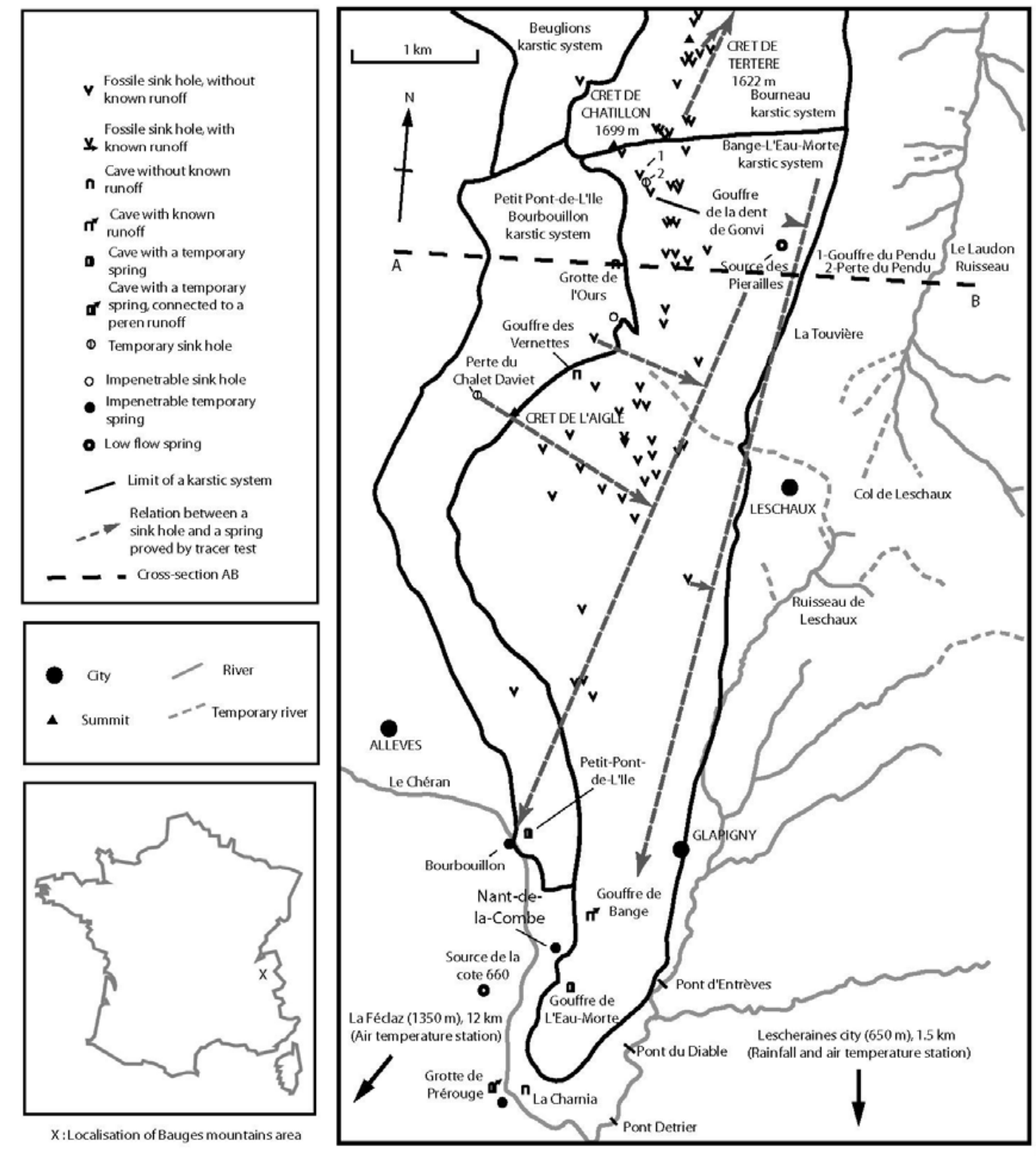

Fig. 1. Surface geology of the Semnoz mountain area, location of Bange-L'Eau-Morte karstic system, Nant de la Combe outlet, precipitation, runoff gauge and temperature stations. 
mountains (Fig. 1). From a stratigraphic and tectonic point of view, the structure of the system is simple: more than $90 \%$ of its lithology is Urgonian limestone and no major faults affect the anticline limestone structure. The Bange l'Eau Morte karstic system (BLMKS) is a small forested catchment of $12.3 \mathrm{~km}^{2}$, ranging in altitude from 640 to 1699 $\mathrm{m}$ a.s.l with a mean altitude of $1225 \mathrm{~m}$ a.s.l.; the basin can be considered as a mid-altitude basin exposed to a mountainous climate. The lateral limits of the system are well known from tracing and field campaigns (Lepiller, 1976). The well developed epikarst is characterised by features such as doline, sinkholes and caves (Fig. 2). The spring called Nant de la Combe, situated under the saturated zone at $647 \mathrm{~m}$ a.s.l., is the only continuous outlet. Mangin (1982) and Marsaud (1996) describe this system as an unary system because the surface catchment is composed mainly of permeable karstified limestones (96\%). The recharge of the system is mostly diffuse, with infiltration from the karstified limestones to the unsaturated zone. Thus, the system comprises a main conduit system developed from a few sinkholes at the interface between the karstic and nonkarstic parts of the catchment surface.

Input to the system is discontinuous in time because 30 to $50 \%$ of precipitation is stored as snow on the catchment.

Water transits to the spring through the epikarst, the unsaturated zone and the saturated zone. While some of the water reaches the spring rapidly by immediate infiltration during flood events, most is retained in the epikarst and in the unsaturated zone by capillarity. There are three different processes of infiltration:

(1) in summer, a non-linear rainfall-runoff relationship because of strong effective evapotranspiration (ET),

(2) in spring and autumn, a more linear rainfall-runoff relation as a result of a reduction of ET,

(3) in winter, runoff is highly controlled by diurnal air temperature fluctuations and snowmelt.

During major flood events, some $4 \%$ of the rainfall infiltrates immediately and underground runoff is also fed by temporary overland flow on the non-karstic part of the catchment. The specific runoff of the system is about $27.31 \mathrm{~s}^{-1} \mathrm{~km}^{2}$ (a discharge of $2.4 \mathrm{~mm} \mathrm{day}^{-1}$ ) for an average rainfall of about $5.0 \mathrm{~mm}$ day $^{-1}$ (Lepiller, 1980).

\section{Description of data and periods studied}

Because of the complexity and heterogeneity of karstic systems (and the processes involved), time-series analyses based on an input-output approach give valuable information on the hydrological functioning. Purposely, long-term series of rainfall, air temperature, runoff and natural tracers have been recorded. In the present study, a single raingauge is used, situated at Lescheraines (at an

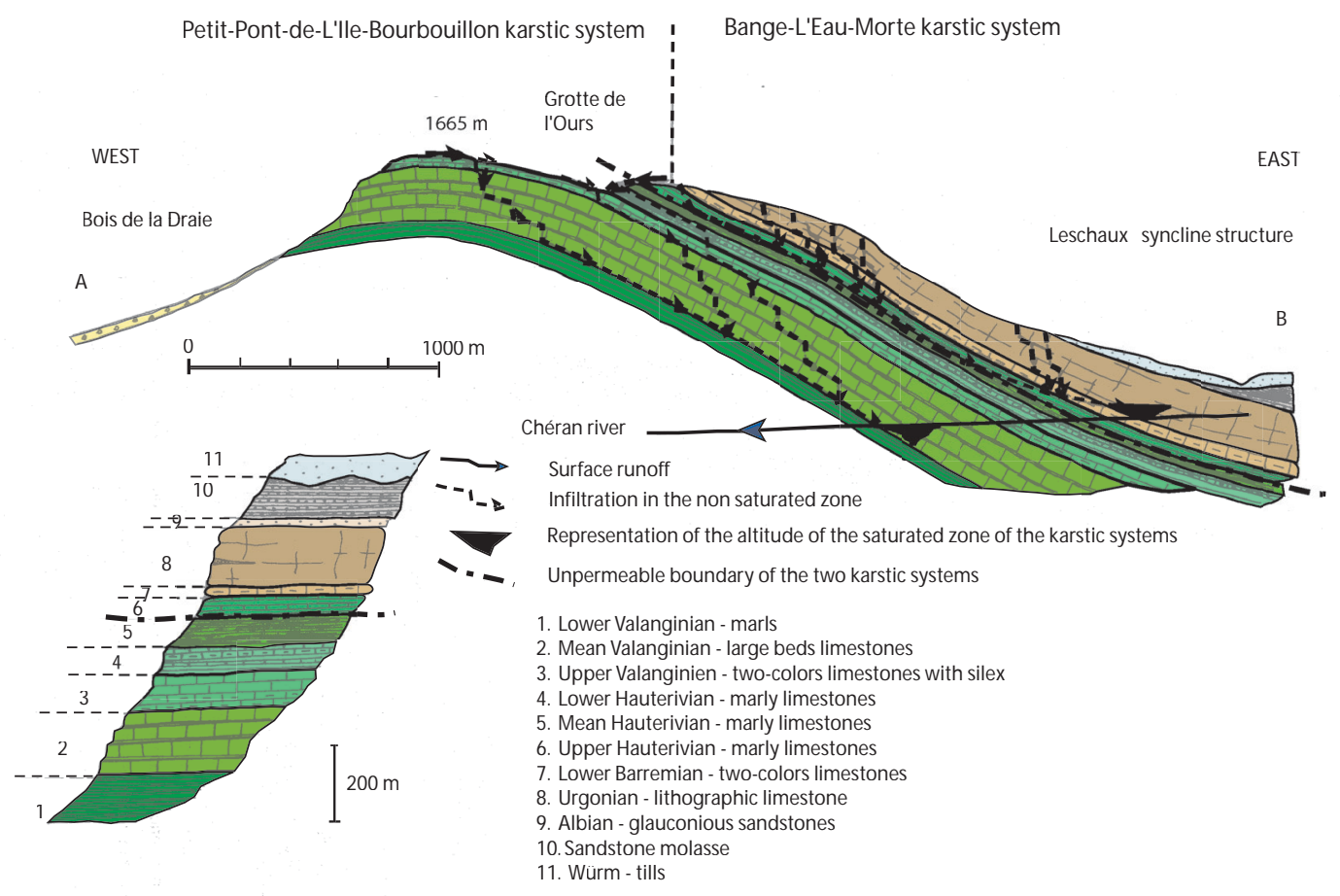

Fig. 2. AB cross-section, perpendicular to the axis of the anticline structure the Semnoz mountain. 
altitude of $650 \mathrm{~m}$ a.s.1., $1.5 \mathrm{~km}$ from the $B L M K S)$. Lepiller's (1980) study of the precipitation of the region over two years, using ten gauges sited between $422 \mathrm{~m}$ and $1650 \mathrm{~m}$ around and on the Semnoz mountain, enables the Lescheraines station to be considered representative of rainfall events and rainfall rates on the overall catchment. In spring, the main outflow occurs at the Nant de la Combe but during major flood events (15\% of days during the 1981-1998 daily runoff series), an intermittent overflow at L'Eau-Morte starts functioning. Runoff at this outlet has been incorporated in the water level-outflow calibration relationship at Nant de la Combe and this outflow constitutes the total outflow (output) of the karstic system. Air temperature affects the functioning of the system: during winter, most precipitation accumulates as snow and, in spring, floods are due to snowmelt. Daily time-series of rainfall, runoff, air temperature (from 1981 to 1998), several hourly or halfhourly runoff series and a few hourly air temperature and rainfall series were available (Table 1 ). The hourly airtemperature station was chosen because its altitude (1350 m) was more representative of the mean altitude of the surface of the catchment (1225 m). Figure 3 shows some of these time-series. Two periods in particular were studied here: P 1, 1981-1988 (Fig. 3a and d) and a wet period, P 2, 06/1991-02/1992 (Fig. 3b and e), A summer recession period (Fig. 3c) and a snowmelt runoff period (Fig. 3f) are also shown.

\section{Step-by-step methodology for studying the hydrodynamical functioning of karstic systems}

In the following, it will be considered that karstic systems consist of three parts: (i) the non-karstic surface of the catchment (impluvium), (ii) the permeable infiltration zone (unsaturated area) and (iii) the permanently saturated zone (saturated area). The input of the system is rainfall and the output is the outflow from the spring. From a global to a very detailed point of view, the present analysis includes

Table 1. Precipitation, runoff and air temperature measurement stations used in the analysis.

\begin{tabular}{llll}
\hline Location & Variable & Annual mean & Period \\
\hline Nant de la Combe - Allèves $(647 \mathrm{~m})$ & Runoff & $880 \mathrm{~mm}$ & $1981-1998$ \\
Lescheraines $(650 \mathrm{~m})$ & Rainfall & $1825 \mathrm{~mm}$ & $1981-1998$ \\
Lescherianes $(650 \mathrm{~m})$ & Temperature (daily) & $8.7^{\circ} \mathrm{C}$ & $1981-1998$ \\
La Feclaz $(1350 \mathrm{~m})$ & Temperature (half-hourly) & - & $05 / 2001-06 / 2002$ \\
\hline
\end{tabular}
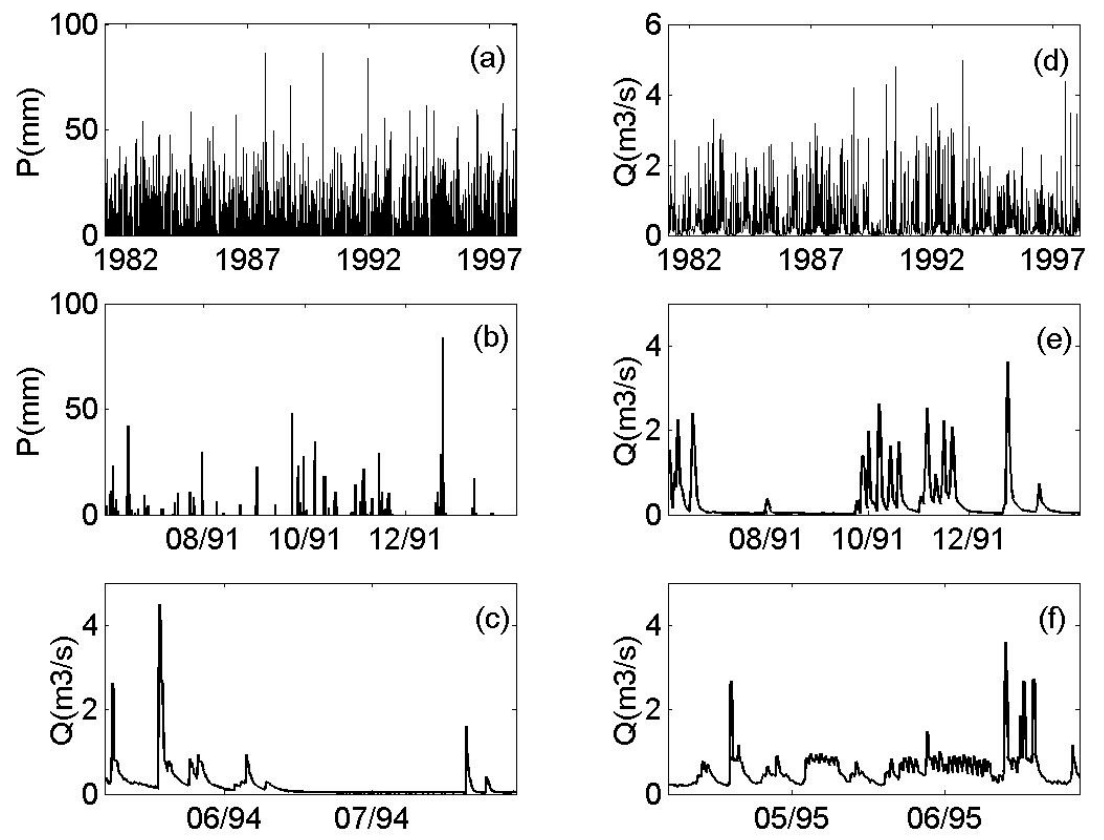

Fig. 3. (a) daily rainfall and (d) daily runoff for period P1, (b) daily rainfall and (e) daily runoff for period P2, (c) half-hourly runoff during summer recession and (f) half-hourly runoff during snowmelt, of Nant de la Combe outlet. 
the study of recession curves (Mangin, 1970, 1975) and the study of the relationships between rainfall, air temperature and runoff series using correlation and spectral analysis (Mangin, 1981, 1984) as well as continuous and discrete wavelet analysis (Labat, 2000; Labat et al., 1999a, b, 2000). The originality of this study is the compilation of these techniques, which are briefly described here.

\section{RECESSION CURVES}

The use of recession curves has been proposed by Mangin (1970), with a model based on Maillet's law (Maillet, 1905) and constituted by two independent reservoirs representative of the drainage from the permeable infiltration zone to the saturated zone (Fig. 4). The recession curve (total outflow) is given by:

$$
Q=q_{0} \cdot \frac{1-\eta \cdot t}{1+\varepsilon . t}+Q_{R 0} \cdot e^{-\alpha t}
$$

where, $q_{0}$ infiltration flow at $t_{0}$ (flood peak) $\left(\mathrm{m}^{3} \mathrm{~s}^{-1}\right), \alpha$ depletion coefficient $\left(\mathrm{d}^{-1}\right), \eta$ infiltration duration coefficient $\left(\mathrm{d}^{-1}\right), \varepsilon$ heterogeneity of subsurface runoff $\left(\mathrm{d}^{-1}\right)$ and $Q_{R 0}$ interpolated base flow at $t_{0}$. The recession curve is composed of the falling curve (first term in Eqn. 1) and the depletion curve (second term in Eqn. 1) of the system.

The parameter set $(\alpha, \eta, \varepsilon)$ is determined by fitting the simulated recession curves to those observed. The parameter set of recession curves allows the estimation of the main characteristics of a karstic system: the inertial behaviour $(\alpha)$, the infiltration rate $(\eta)$ and the heterogeneity of infiltration $(\varepsilon)$ of the system.

The dynamical volume of storage (in the saturated zone) can be estimated (Mangin, 1970) by:

$$
V_{D Y N}=\frac{Q_{R 0}}{\alpha} \cdot c
$$

with c: 86400 s.d $\mathrm{d}^{-1}$

This volume represents the maximum volume of storage at the beginning of the recession period (Marsaud, 1996). These characteristics give a good indication of the degree of karstification and organisation of the drainage network of the system.

\section{TIME-SERIES ANALYSIS}

The aim of time-series analysis techniques is to determine the following characteristics of a given temporal data set: trend, structures and noise in the series. The trend is linked with the long-term functioning of the system: stationary, non-stationary and periodic phenomena. The structures are linked with the short-term functioning of the system. The noise, composed of very short-term components, is usually ignored by hydrologists, because its analysis requires unconventional time-series analysis techniques. However, noise provides information about stochastic processes, chaotic phenomena and measurement errors. The study of the $B L M K S$ functioning will be based on the analyses of the trend, the structures and the noise of the time-series.

\section{Correlation and spectral analyses}

Time-series analysis (Box and Jenkins, 1974) has been largely applied in hydrology (e.g. Yevjevitch, 1972; Bras and Rodriguez-Iturbe, 1993), especially for forecasting, data control and modelling. But, Mangin $(1981,1984)$ introduced this kind of analysis to study and compare the dynamic behaviour (spring outflow) of karstic systems, in reaction to rainfall or other input variable (temperature, air pressure, sea and terrestrial tide, etc.). Since then, such studies have been applied in karstic hydrology in many case studies (Mangin, 1984; Lepiller et al., 1988; Muet, 1989; Padilla and Pulido Bosch, 1995; Bouchaou et al., 1996; Morales Juberias et al., 1996; Larocque et al., 1998; Bouchaou et al., 2002). A mathematical overview of single and cross correlation and spectral analyses is presented by Mangin (1984) and by Padilla and Pulido Bosch (1995). From a technical point of view, the power spectrum is calculated

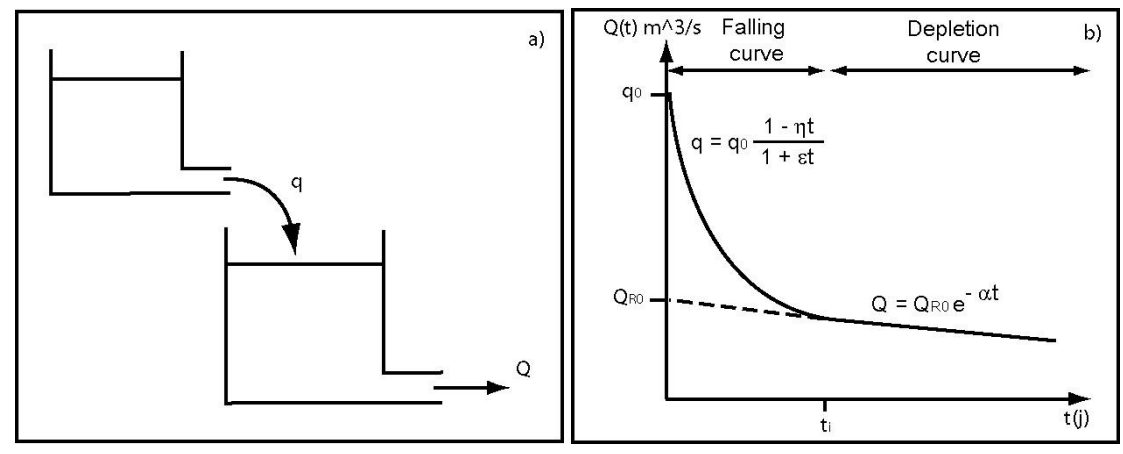

Fig. 4. (a) two reservoirs model and (b) decomposition of recession proposed by Mangin (1970). 
by an indirect technique, because hydrological time-series are non-stationary and are sometimes corrupted by noise. As proposed by Max (1980), Mangin (1984) evaluated the power spectrum of hydrological time-series using the correlogram of the time-series and applying a smoothing window (Tuckey 2), to ensure that the power spectrum values are not biased.

To understand the hydrological functioning of a karstic system, it is assumed to act as a filter capable of modulating the input and that the memory effect of the system (or regulatory effect) represents the way the system modulates the input, either in the short, medium or long term. These effects and the manner in which the system fills or empties are linked strongly to its degree of organisation (karstification), its water storage and its hydrodynamic properties.

As mentioned previously, single and cross correlation and spectral analyses can be used to study information content and the relationship of input and output series. Combining single correlation (timescale) and spectral (frequency scale) analyses, one can identify which characteristics of the input are either maintained, modified or absent in the output series. Then, combining cross correlation and spectral analyses, one can show how the information contained in the input series is transferred into the output series.

\section{Wavelet analysis}

Correlation and spectral analyses provide information on the global functioning of karstic systems, but cannot take into account the temporal variability of hydrological processes, which often lead to a non-stationary and nonlinear functioning of the system. Therefore, wavelet analyses have been introduced to focus on non-stationary structures in the series. For example, here the interest is in short-term structures in the series and in intermittent outflow of the system during snowmelt. Wavelet analysis is a timedependent spectral analysis that decomposes time-series in the time-frequency space to give a timescale representation of processes and their relationships. The dominant modes of variability can, therefore, be identified and their variations studied.

In the earth sciences, wavelet analysis has been applied since the mid-80s (Grossman and Morlet, 1984) but, only since the mid-90s, to climatology and hydrology. Even if applications of wavelet analyses are still rare in hydrology, they have been applied recently to the study of karstic systems (Labat, 2000; Labat et al., 1999a, b, 2000, 2001) and other hydrological fields (Smith et al., 1998; Nakken, 1999; Gaucherel, 2002; Lafrenière and Sharp, 2003). A mathematical overview of wavelet transform and a review of applications is presented by Torrence and Compo (1998) and by Labat (2000).

This study used: (i) continuous time wavelet transforms, that provide a complete timescale representation of localised and transient phenomena occurring at different timescales, and (ii) discrete time wavelet transforms, that allow the time series to be split into timescale domains. In the literature, there are many different graphical representations of wavelet analysis (Nakken, 1999; Labat et al., 2000; Gaucherel, 2002). The representation chosen here can be read as follows: the $x$ axis represents the time and the $y$ axis the corresponding wavelet period of the time-series, at time $t$. The absence or presence of a period is coded by a progressive colour scale, from dark/blue (no component) to bright/red (existing component). A bright line means that the component is stationary.

\section{NOISE ANALYSIS}

The method used to study noise structure is based on the approach described by Mandelbrot and Wallis $(1968,1969)$ and Mandelbrot $(2000,2001)$. The noise corresponds to the short-term components of the signal and is usually considered to be (totally) unstructured. However, the noise of a time-series can be studied, using its spectral density function. Hardy and Beier (1994) present a noise type classification, based on the slope $(\beta)$ of the spectral density function of the time-series studied, plotted in a bi-logarithmic diagram. This analysis allows one to identify if the noise is stochastic or structured and may give the fractal exponent of the time-series. Two types of noises can be distinguished:

- Gaussian noise is characterised by $-1<\beta<1$. $\beta=0$ corresponds to pure white noise, $0<\beta<1$ corresponds to a high-pass filter and $-1<\beta<0$ corresponds to a lowpass filter. Gaussian noise means that the series is composed of independent stochastic variables. The noise contains no information.

- Brownian noise is characterised by $-3<\beta<-1 .-2<\beta<-1$ corresponds to the anti-persistent Brownian noise, with a poor correlation between variables. $-3<\beta<-2$ corresponds to the persistent Brownian noise, with a memory effect and a high correlation between variables. When $\beta<-3$, variables are not stochastic and the noise is structured.

\section{Results}

GENERAL FUNCTIONING OF THE SYSTEM

Recession curves

Six recession curves were considered for this system during 
Table 2. Characteristics of recession curves of the BLMKS, compared to the Aliou system (Mangin, 1975).

\begin{tabular}{lllll}
\hline Parameters & Min. & Max. & Mean & Aliou system \\
\hline Depletion coefficient $-\alpha\left(\mathrm{j}^{-1}\right)$ & 0.0126 & 0.0247 & 0.02 & 0.03 \\
Infiltration coefficient $-\eta\left(\mathrm{j}^{-1}\right)$ & 0.077 & 0.125 & 0.10 & 0.07 \\
Flow heterogeneity coefficient $-\varepsilon\left(\mathrm{j}^{-1}\right)$ & 1.0 & 9.2 & 4.4 & 13.2 \\
Dynamical volume $-\mathrm{Vd}\left(\mathrm{m}^{3}\right)$ & 170000 & 260000 & 210000 & 100000 \\
\hline
\end{tabular}

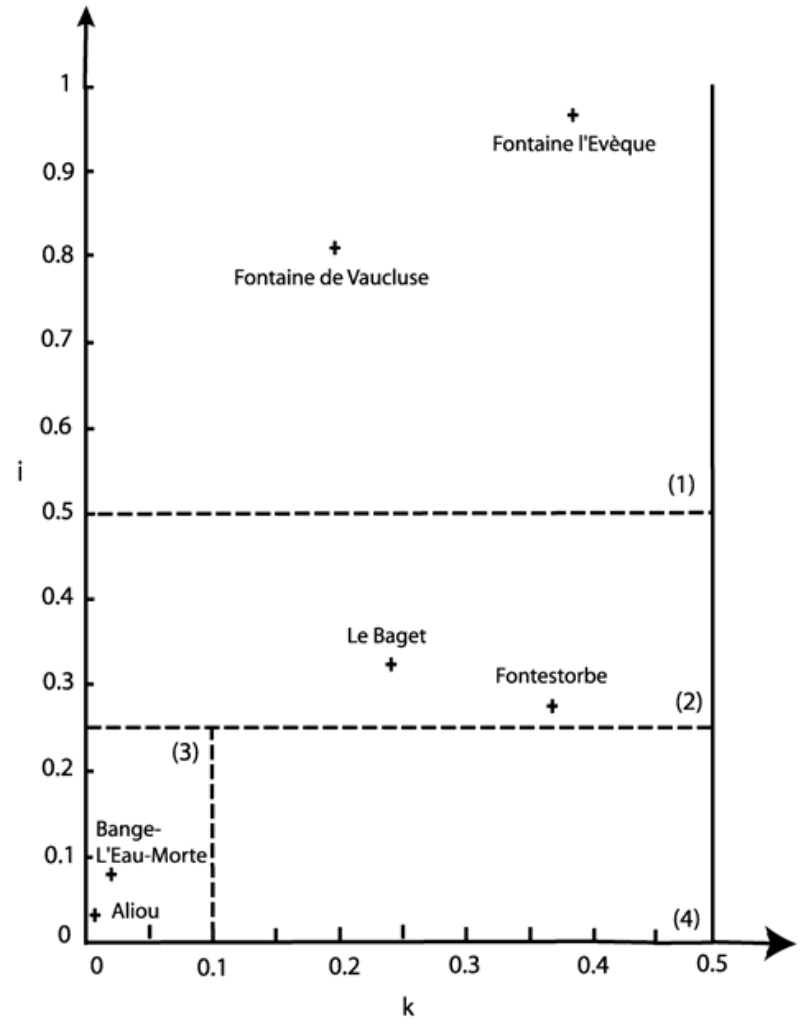

Fig. 5. Position of Bange-L'Eau-Morte karstic system and comparison with other well-known French karstic systems, in the graphic classification proposed by Mangin (1975). [ 1, 2, 3, 4] corresponds to the four type of karstic system functioning identified by recession curves.

long term summer recessions after important spring flood periods. Characteristics and results are presented in Table 2. A high and stable depletion coefficient $(\alpha)$, a short infiltration duration coefficient $(\eta)$ and a high flow heterogeneity coefficient $(\varepsilon)$ indicate that the drainage of the system is good and that there is a high degree of karstification. Moreover, this system is characterised by a very low dynamic storage volume (only $210000 \mathrm{~m}^{3}$ ). These characteristics are similar to those of the Aliou karstic system (Ariège, Pyrénées, France) and Fig. 5 shows that the $B L M K S$ can be placed in the graphic classification of karstic systems proposed by Mangin (1975).
Correlation and spectral analyses, noise analysis

For these analyses the input parameter is only rainfall because (i) there were too few observations for a good estimation of the evapotranspiration in the karstic system and (ii) evapotranspiration is part of the infiltration processes and, hence, effective rainfalls could not be considered as the inputs to the system (Pulido Bosch et al., 1987). For the study, two different periods were chosen to show the influence of snowmelt on the functioning of the system: (i) period P1, the 1981-1998 continuous daily series and (ii) period P2, the wet part of the hydrological 1991-1992 cycle.

The correlograms of the period P1 rainfall series (Fig. 6a and b) show the quasi-stochastic characteristics of rainfall at long and short terms. Spectral density functions (Fig. 6d and e) also show the lack of structure in the time-series. Nevertheless, in the shorter term, the correlation and spectral density functions (Fig. 6c and f) show some small structures in the rainfall. These structures could be linked to a particularity of the local meteorology and a similar effect was found for other rainfall series in the Bauges mountains and in the neighbouring Bornes mountains (Mondain, 1991).

In the long term, even if the rainfall exhibits no structure, the correlogram function of the P1 period runoff series (Fig. 7a) shows a quick decrease of the cross-correlation coefficient $\left(r_{k}\right)$ and a typical annual cycle. Even if this annual component seems to be attenuated, this shows the influence of the annual variation of actual evapotranspiration on the catchment storage in the system and on its inertial response to rainfall and the storage of rainfall in the snow pack. The spectral density function (Fig. 7d) shows the snowmelt processes, with clear annual and semi-annual components. In the short term, the correlogram functions of P1 and P2 periods (Fig. 7b and c) again show a very quick decrease of $\mathrm{r}_{\mathrm{k}}$. For these two periods the shapes of correlograms differ, because the 18-year runoff series smoothes the correlogram function. For both periods, the memory effect (time length when the runoff stops being auto-correlated, which is when $\left.r_{k}<0.2\right)$ is about seven days. This brief memory effect shows that the auto-correlation of streamflows is very short in the time, which indicates low catchment storage capacity. In 

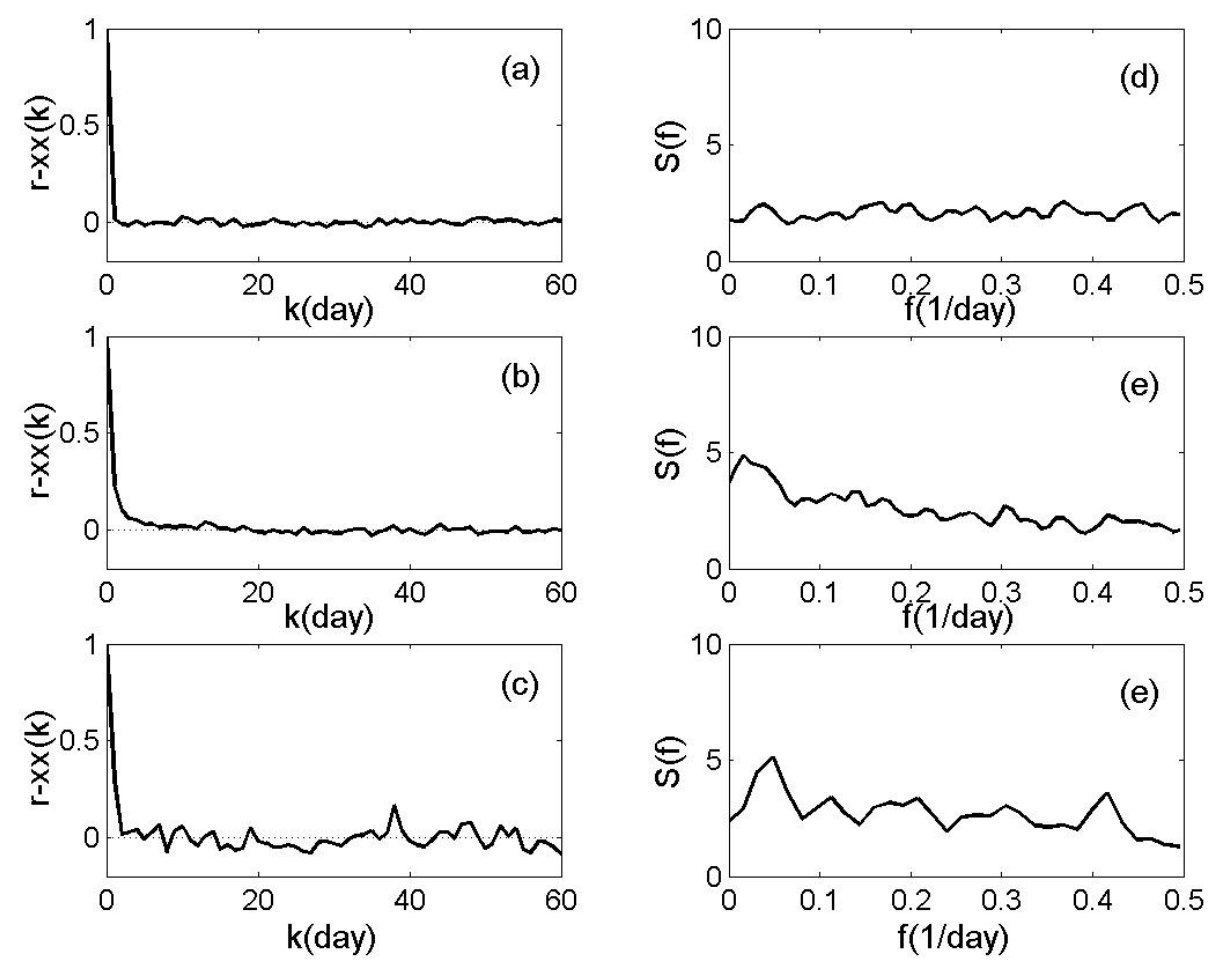

Fig. 6. Correlograms and spectral density functions obtained for the rainfall series: (a)/(d) long term (truncature: 1250 days, step: 10 days) and (b)/(e) short term analysis (truncature: 125 days, step: 1 day) for period $P 1,(c) /(f)$ short term analysis (truncature: 62 days, step: 1 day) for period $P 2$.
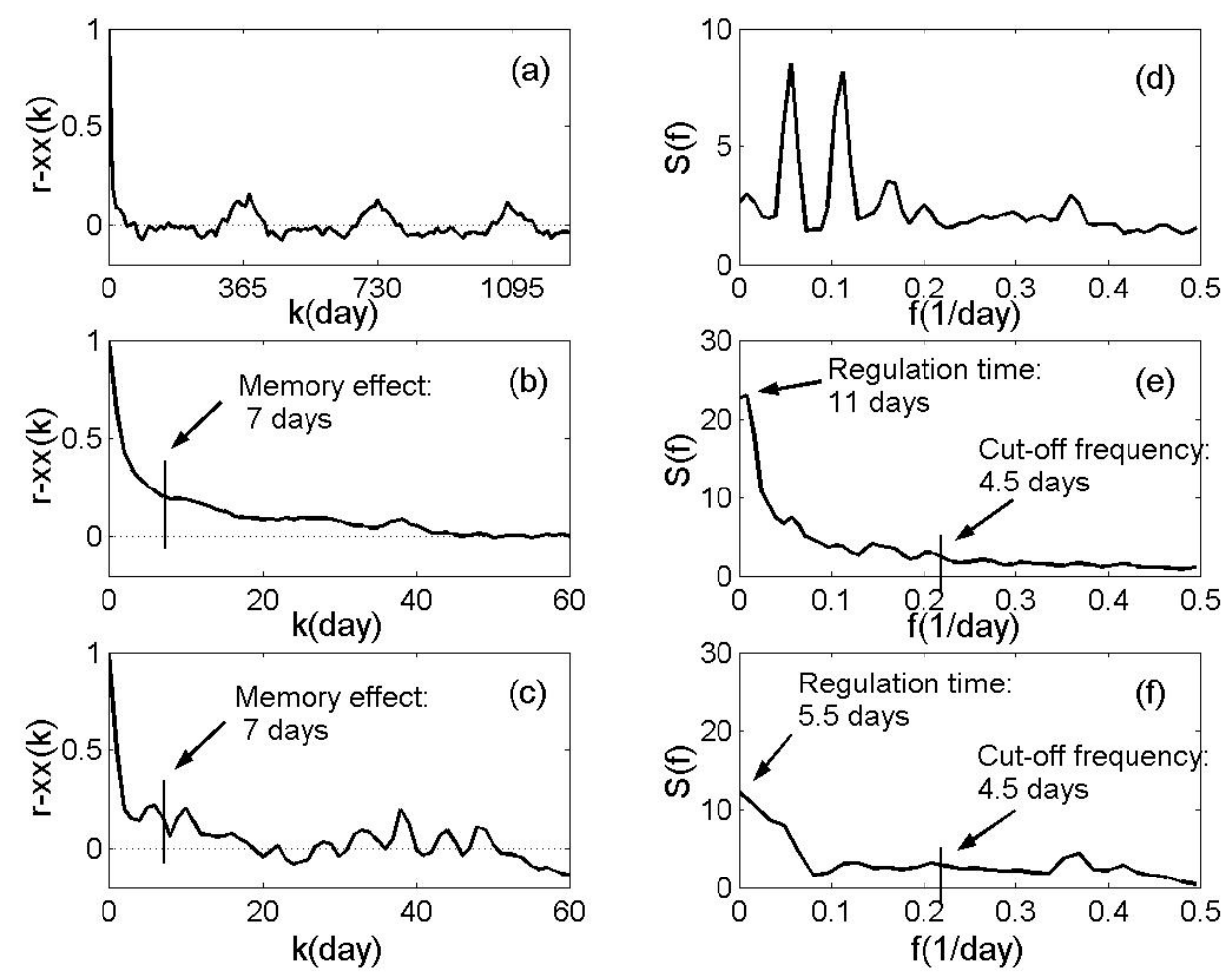

Fig. 7. Correlograms and spectral density functions obtained for the runoff series: (a)/(d) long term (truncature: 1250 days, step: 10 days) and (b)/(e) short term analysis (truncature: 125 days, step: 1 day) for period $P 1,(c) /(f)$ short term analysis (truncature: 62 days, step: 1 day) for period $P 2$. 
the same way, the spectral density functions (Fig. 7 e and f) show that the system has for both periods a cut-off frequency (when $\mathrm{S}<1$ ) of about 4.5 days. This means that all rainfall events of $<4.5$ days are filtered by the system. However, the regulation time (length of time where the output is influenced by the input, which corresponds to the value of $\mathrm{S}(0) / 2)$ is different for the two periods. The $\mathrm{P} 1$ period runoff series has a regulation time of about 11 days and the P2 period runoff series has a regulation time of about 5.5 days. This difference comes from the influence of snow on the system, which gives more inertia, due to external storage of water. This analysis shows that the system drains well and that the storage capacity of the catchment is low. Snow affects the functioning of the system and gives it some inertia. The study of the noise of P1 period rainfall (Fig. 8a) and runoff (Fig. 8b) series shows that: (i) the rainfall series noise is Gaussian, so that it can be considered as a pure stochastic and non-structured phenomenon and (ii) the runoff series noise is Brownian, which means that runoff can be considered as a stochastic but structured phenomenon, with fractal characteristics (the noise function is mostly a line).

The behaviour and the response function of the karstic system can be characterised by the cross-correlation and cross-spectral analyses between precipitation and streamflow series. Since no (or few) structures were found in the rainfall series and the noise of this series is Gaussian, rainfall is considered as a random process. The crosscorrelation analysis can be considered as the response function of the system to a Dirac peak. The cross-correlation functions of the P1 and P2 periods (Fig. 9a and b) are characterised by (i) a sharp, individual peak with a response
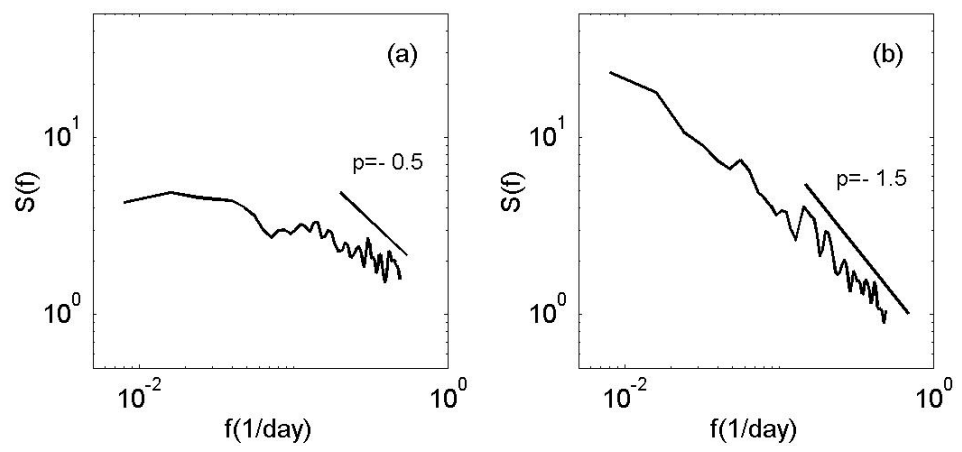

Fig. 8. (a) noise of the rainfall series and (b) noise of the runoff series for period P1.
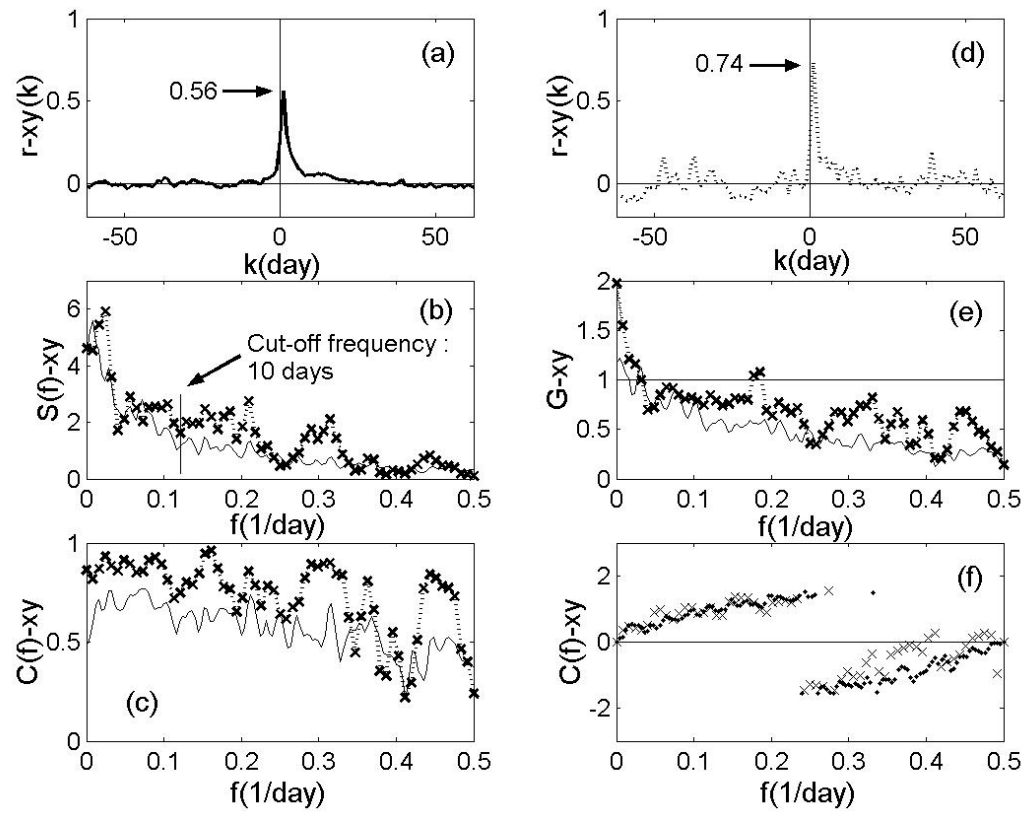

Fig. 9. Cross-correlation functions obtained for (a) period PI and (d) period P2. Cross amplitude functions (b), Coherence functions (c), Gain functions (e) and Phase functions (f) for period PI (plain or dots) and period P2(cross). 
time of one day, decreasing quickly (in ten days) and then (ii) a slower decrease (from ten to twenty days). The first part of the response function characterises a really good response of the system to rainfall due to good transmissivity and good drainage in the system, which corresponds to the quickflow component. The second part of the response function characterises the capacitive effect of the system, probably due to late infiltration, the baseflow component and the snow pack during winter. The cross-correlation functions of the two periods are very similar. However, the main difference is the maximal value of the peak $\left(\mathrm{r}_{\mathrm{xy}}(1)\right.$, respectively equal to 0.56 and to 0.74 ), which indicates again the inertial effect of the snow pack.

For $\mathrm{P} 1$ and $\mathrm{P} 2$ periods, the two cross-amplitude functions (Fig. 9c) have a cut-off frequency of about 4.5 days and 3 days respectively. This indicates that the rainfall-runoff relationship is linear on a long timescale, but is clearly nonlinear at a shorter timescale. The coherence function indicates the degree of linearity of the response of the system. Figure $9 \mathrm{c}$ shows for $\mathrm{P} 1$ period runoff series a high and stable value (around 0.65 ) and, for the P2 runoff series, a higher value in the long term (around 0.9 ) and a lower and variable value in the short term. This indicates again that the rainfallrunoff relationship is linear at long term time-steps, for the P2 period. The effect of the snowpack is expressed by the loss of coherence, which decreases the degree of linearity of the rainfall-runoff relationship. The gain function shows how the system amplifies or attenuates the input signal for different frequencies. Figure 9e shows that there is a little amplification of the input signal at a long term time-step and a slight attenuation of the input signal at a short term time-step. This characterises a system with high transmissivity and low catchment storage capacity, because there is no attenuation of the input by the system on long term time-steps. There is also a strong late infiltration through the non-saturated zone, shown by little mid-term attenuation. The difference between the P1 period runoff series and the P2 period runoff series is shown by better amplification, on the long term time-step, of the $\mathrm{P} 2$ runoff series. Padilla and Pulido Bosch (1995) consider that a gain function of 1 corresponds to the duration of the impulse response of the aquifer baseflow component while a value of 0.4 corresponds to the duration of the quickflow component; hence, it is possible to estimate the duration of gravitational water runoff. The baseflow and quickflow responses are about 30 days and 4 days respectively. These durations correspond to well drained systems, with limited water storage capacity (Padilla and Pulido Bosch, 1995).

Finally, the phase function represents the travel time of the information. For both periods, the lag between rainfall and runoff is about one day, which indicates again how well drained the system is, with low water storage capacity and a quick response to rainfall events.

\section{Wavelet analyses}

Wavelet analyses were applied to study non-stationary processes, in particular, phenomena precisely situated in time. First to be studied were the long-term rainfall-runoff relationships and then the air temperature-runoff relationship during snowmelt. Thirdly, typical short term runoff oscillations, induced by structural particularities of the system, were addressed.

Figure $10 \mathrm{a}$ and $\mathrm{b}$ shows the continuous wavelet transform of the P1 period rainfall and runoff series. On short timescales (less than 16 days), high frequency structures are visible in the rainfall series (Fig. 10a) but less so in the runoff series (Fig. 10b) because of the low-pass property of catchment storage. This reveals useful information on the (a)

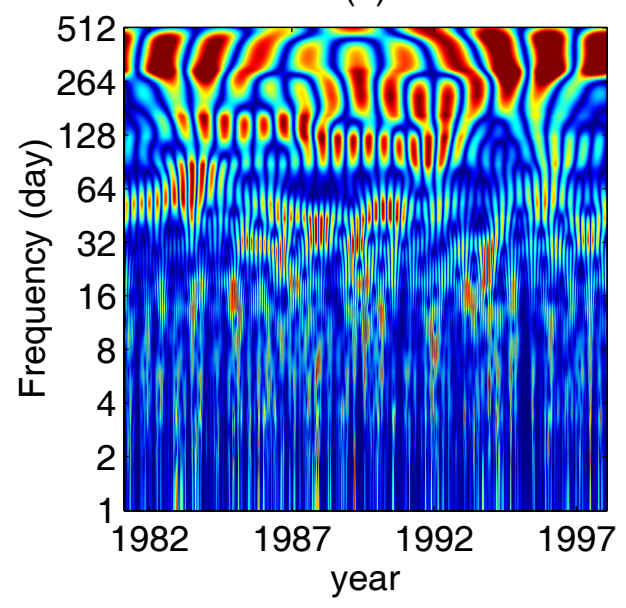

(b)

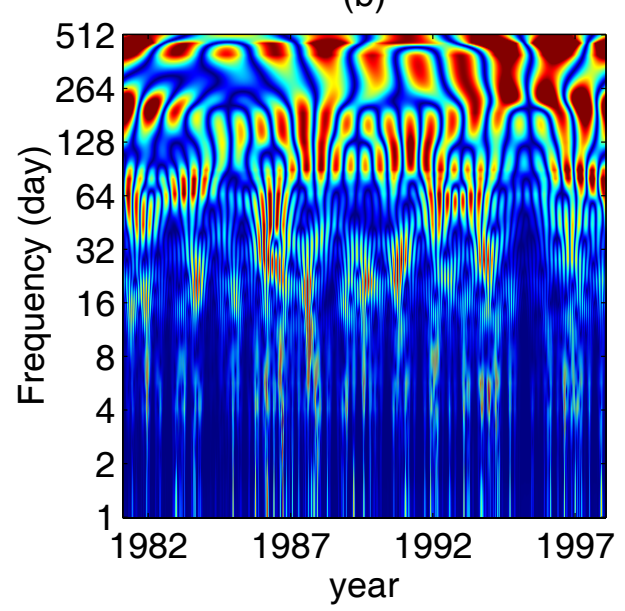

Fig. 10. Continuous wavelet transform of the (a) 1981-1998 rainfall time-series and (b) 1981-1998 runoff time-series. 
transmissivity and the degree of karstification of this system. At middle timescales (between 32 and 128 days) nonstationary structures are visible both in the rainfall and in the runoff. These mid-term non-stationary structures, typical of the region studied, were also found by Mondain (1991). Wavelet analyses localise these structures more precisely than correlation and spectral analyses. Interestingly, there is a particular feature of the system, which, in higher timescales, seems to operate a transfer from rainfall components to runoff components. At larger timescales, a light non-stationary annual (between 256 and 512 days) component exists for the rainfall series and, with higher intensity and stationarity, for the runoff series. The semiannual structure (between 128 and 256 days) corresponds to the snowmelt functioning of the karstic system. At middle and large timescales, the components in the rainfall are nonstationary and are characterised by a variable frequency. For example, components higher than 64 days disappeared during the years 1983-1984 and 1994-1995.

\section{FUNCTIONING DURING SNOWMELT}

The study of the snowmelt period is particularly interesting, especially when coupled with a geochemical study, because the system is fed by a homogeneous water depth, coming from the snowmelt. During this period the system receives more or less one-third of the total annual rainfall, which contributes to its high degree of saturation and to a high runoff. The saturation of the system allows good drainage and a very good response to temperature (snowmelt) fluctuations.

Figure 11a and d show the half-hourly air temperature and runoff series during snowmelt. The spectral density functions (Fig. 12a and c) during snowmelt show that the system is characterised by daily fluctuations in runoff, as snowmelt is caused by the diurnal variation in temperature. The response of the system is good and a decrease in temperature below $0^{\circ} \mathrm{C}$ is followed by a decrease in runoff, the diurnal variation of which ceases. The $8 \mathrm{~h}$ and $12 \mathrm{~h}$ components respectively in the temperature and runoff series are undoubtedly due to the asymmetric variation of air temperature during the day and to the inertia of the snow pack, which causes the runoff response to be asymmetric (Chauve et al., 1990). The cut-off frequency of the runoff series is high, at about ten hours, which indicates that short term temperature components are filtered by the inertia of the snow pack, which can be considered as a low pass filter of temperature fluctuations. Continuous and discrete wavelet transforms of the air temperature and the runoff series are presented, respectively, in Fig. 20b and e and in Fig. 20c and $f$. The wavelet transform of the air temperature series shows a clear daily component, with low intense sub-daily and non-stationary components. The wavelet transform of the runoff series also shows a daily component, which, however, is non-stationary and varies between 12 hours and 32 hours, depending on whether or not the air temperature
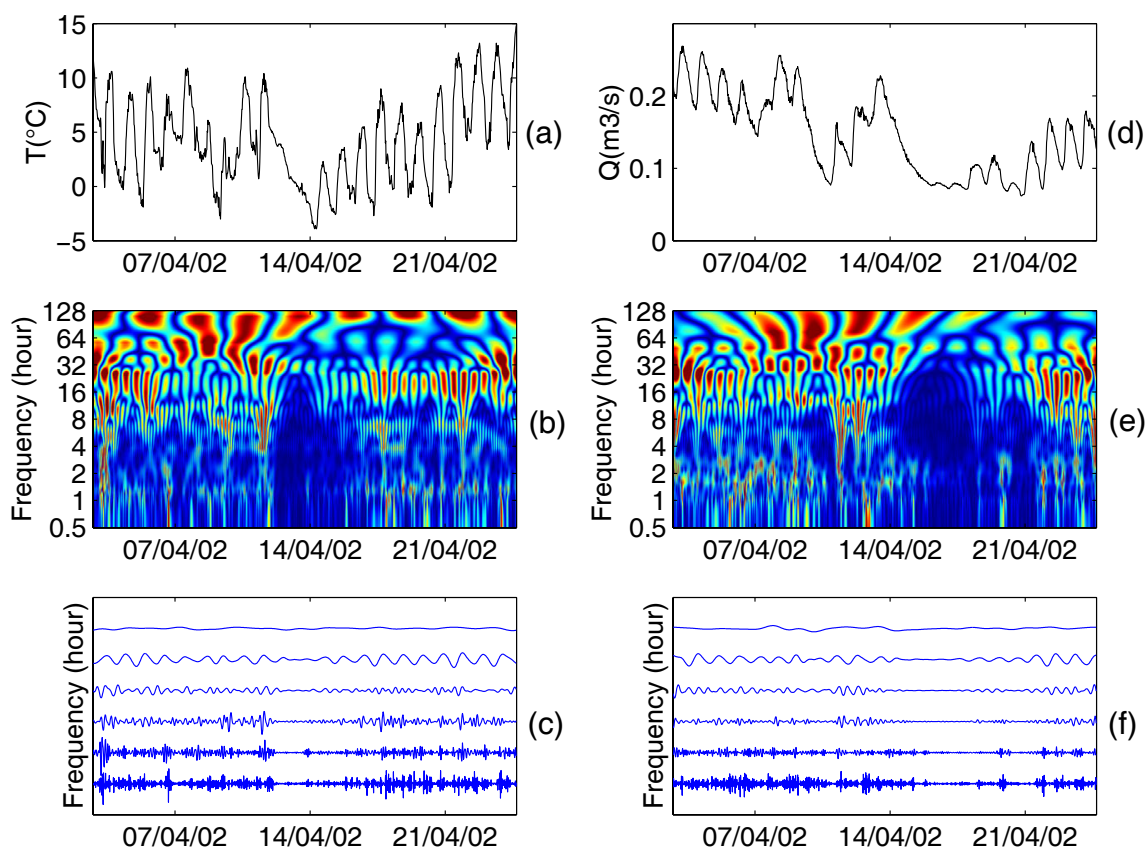

Fig. 11. Half hourly (a) air temperature and (d) runoff during snowmelt period and respective continuous/discrete wavelet transform of half hourly $(b / c)$ air temperature and $(e / f)$ runoff. 

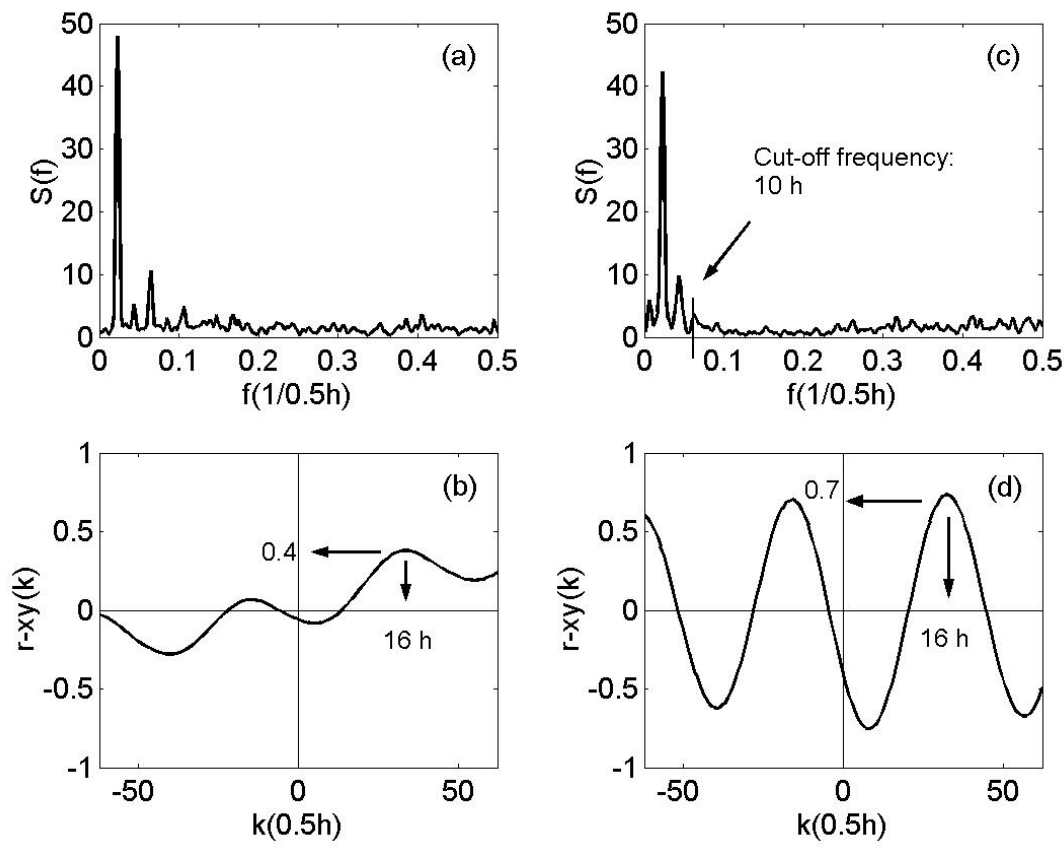

Fig. 12. Spectral density functions (truncature: 120 hour, step: 0.5 hour) of (a) the air temperature series and (c) the runoff series during snowmelt period (the series have been differenciated in order to filter the tendancy). Cross-correlation functions (truncature: 120 hour, step: 0.5 hour) of (b) the air temperature and runoff series and (d) the $16 \mathrm{~h}$ components of the air temperature and runoff series, isolated thanks to discrete wavelet transform, during snowmelt period.

is above $0^{\circ} \mathrm{C}$. At a short timescale, there are some high frequency structures ( $1 \mathrm{~h}, 2 \mathrm{~h}$ components) in the runoff series. This may indicate the complexity of the water transit through the karstic system to the spring outlet. The crosscorrelation function of the air temperature and the runoff series (Fig. 12b) indicates a poor relationship, with a low correlation coefficient (0.4). However, through discrete wavelet transform, a particular component of the series can be isolated. The 16-hour components of the air temperature and runoff series were isolated (the closest component to 24h) and the cross-correlation determined (Fig. 12d). The relatively high correlation coefficient $(0.7)$ indicates that the relationship between these two variables is good, on a daily timescale. Moreover, the response time of spring runoff to temperature is very short, about $16 \mathrm{~h}$. This shows that drainage of the system is good and that major parts of the unsaturated zone are quasi-saturated during this period.

\section{PARTICULAR FEATURES OF THE HYDROGRAPH}

A detailed study of the hydrographs of the runoff series shows some particular streamflow values $(0.26 ; 0.45 ; 0.55$; $\left.0.75 ; 0.85 \mathrm{~m}^{3} \mathrm{~s}^{-1}\right)$, almost always characterised by a peak and an oscillation in the runoff. Figure 13 shows a runoff series (in this case during a snowmelt period) and its continuous and discrete wavelet transforms. Such oscillations can be found during all periods of the year.
During high floods, it is not possible to identify these characteristics, because the order of magnitude of these oscillations is small compared with those of runoff during floods. The continuous and discrete wavelet transforms indicate an intense daily structure with a non-stationary high frequency component (about one or two hours), when the runoff is between 0.8 and $0.9 \mathrm{~m}^{3} \mathrm{~s}^{-1}$. This value corresponds to the flow of the L'Eau-Morte. In that case, through wavelet analysis, it is possible to focus on a particular feature of the system. This feature is the result of the particular internal structure of the karstic system close to the outlet.

\section{Discussion and conclusions}

This paper presents the Bange-L'Eau-Morte karstic system and contributes insights into its functioning. The different methods used, from classical recession curve analyses to wavelet analyses enable characteristics of karstic systems to be identified and different systems to be compared objectively. The methods were presented briefly, because one of the aims of this paper was to introduce them together and use a step-by-step approach to apply each type of complementary analyses. To the author's knowledge, this paper is the first to summarise the application of these different methods, on the Alpine Bange-L'Eau-Morte karstic system. Now, this system is a well-documented case study, which can be compared with its Pyrenean cousins of Aliou, 


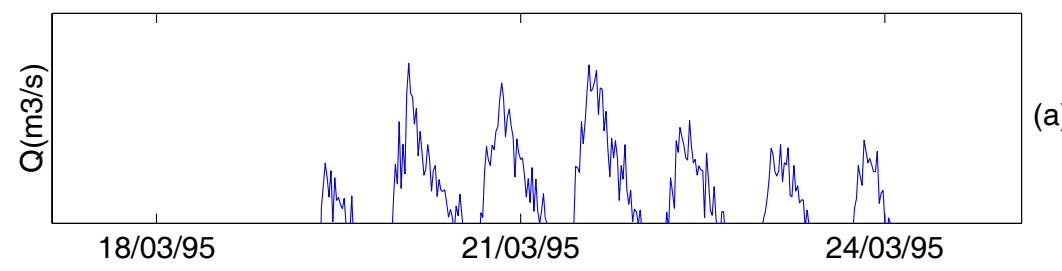

(a)
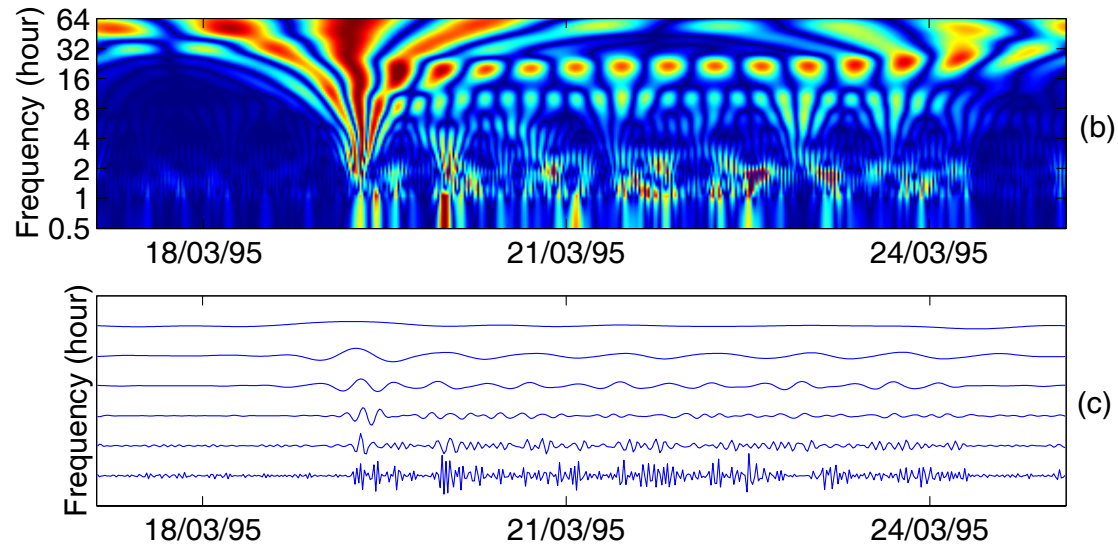

Fig. 13. (a) half hourly runoff series during 1995 snowmelt period, (b) continuous wavelet transform and (c) discrete wavelet transform.

Baget and Fontestorbes karstic systems, on which these methods have been developed step by step, since the 1970s.

The classical application of recession curves, correlation and spectral analysis to the study of the hydrograph of the Nant de la Combe spring gives a comprehensive overview of the functioning of the system, characterised by limited catchment storage capacity, with clear snowmelt functioning in the long term and reactive and dynamic behaviour in the short term. Even if it could be argued that these different analyses lead to similar conclusions, they provide different points of view on the functioning of this karstic system. In the present case, all the conclusions converge, because the structure of this system is particularly simple and well drained. However, on larger karstic systems, with a more complex functioning, these analyses may identify different properties of the karstic system, a more detailed appreciation of the functioning of which is given by wavelet analysis. Rainfall and runoff are both characterised by highly nonstationary and timescale-dependent behaviour in the long term. In the shorter term, wavelet analysis can identify the excellent temperature-runoff relationship during the snowmelt period, with a delay of about $16 \mathrm{~h}$. Moreover, some features of the system, undoubtedly linked to the structure and the development of the system close to the outlet, were characterised by oscillations in the runoff for particular values.

\section{Acknowledgments}

The authors thank Carmen de Jong and Javier Corripio for the opportunity to publish this paper and the reviewers for their helpful comments. Thibault Mathevet warmly acknowledges Bénédicte Augeard, Noémie d'Ozouville, Charles Perrin and members of the International Club of Social Hydrology for their scientific support and encouragements.

\section{References}

Bouchaou, L., Mangin, A., Chauve, P., Mania, J. and Aboufirassi, M., 1996. Contribution of hydrodynamic methods to the study of a karstic aquifer (Beni-Mellal Atlas, Morocco). Geodin. Acta, 9, 170-176.

Bouchaou, L., Mangin, A. and Chauve, P., 2002. Turbidity mechanism of water from a karstic spring: example of the Ain Asserdoune spring (Beni Mellal Atlas, Morocco). J. Hydrol., 265, 34-42.

Box, G.E.P. and Jenkins, G.M., 1974. Time series analysis, forecasting and control. Revised Edn. Holden Day, San Francisco, USA. 575pp.

Bras, R.L. and Rodriguez-Iturbe, I., 1993. Random functions and hydrology. Dover Pub. Inc., New York, USA. 559pp.

Chauve, P., Mania, J. and Moindrot, D., 1990. Modalités de la fonte de neige en moyenne montagne et alimentation du karst sous-jacent. In: Hydrology in Mountainous Regions. IHydrological Measurements; The Water Cycle, H. Lang and A. Musy (Eds.) IASH Publication no. 193.

Gaucherel, C., 2002. Use of wavelet transform for temporal characterisation of remote watersheds. J. Hydrol., 269, 101121. 
Grossman, A. and Morlet, J., 1984. Decomposition of Hardy functions into square integrable wavelet constant shape. SIAM J. Math. Anal., 15, 723-736.

Hardy, H.H. and Beier, R.A., 1994. Fractals in reservoir engineering. Ed. Word Scientific. 359pp.

Labat, D., 2000. Non-linéarité et non-stationnarité en hydrologie karstique. Ph.D. Thesis, INP, Toulouse, 220pp.

Labat, D., Ababou, R. and Mangin, A., 1999a. Wavelet analysis in karstic hydrology. 1st part: univariate analysis of rainfall rates and karstic spring runoffs. C. R. Acad. Sci. Ser II-A, 329, 873879.

Labat, D., Ababou, R. and Mangin, A., 1999b. Wavelet analysis in karstic hydrology. 2nd part: rainfall-runoff cross-wavelet analysis. C. R. Acad. Sci. Ser II-A, 329, 881-887.

Labat, D., Ababou, R. and Mangin, A., 2000. Rainfall-runoff relations for karstic springs. Part II: continuous wavelet and discrete orthogonal multiresolution analyses. J. Hydrol., 238, 149-178.

Labat, D., Ababou, R. and Mangin, A., 2001. Introduction of wavelet analyses to rainfall/runoffs relationship for a karstic basin: The case of Licq-Atherey karstic system (France). Ground Water, 39, 605-615.

Lafrenière, M. and Sharp, M., 2003. Wavelet analysis of interannual variability in the runoff regimes of glacial and nival stream catchments, Bow Lake, Alberta. Hydrol. Process., 17, 1093-1118.

Larocque, M., Mangin, A., Razack, M. and Banton, O., 1998. Contribution of correlation and spectral analyses to the regional study of a large karst aquifer (Charente, France). J. Hydrol., 205, 217-231.

Lepiller, M., 1976. Résultats et interprétation de cinq opérations de traçage effectuées sur les systèmes karstiques du Semnoz et de la montagne de Bange - Bois de Prépoulain (Massif subalpin des Bauges, Savoie et Haute-Savoie, France), 2éme Colloque d'Hydrologie en Pays Calcaires, Besançon, France. 251-262.

Lepiller, M., 1980. Contribution de l'hydrochimie à la connaissance du comportement hydrogéologique des massifs calcaires. Etude de quelques systèmes karstiques du massif du Semnoz et de la région d'Annecy (Savoie, Haute-Savoie, France). Ph.D. Thesis, University of Grenoble, France. 488pp.

Lepiller, M., 1982. La capacité de stockage dans la zone nonsaturée des aquifères karstiques. Estimation et conséquences pour la localisation de la dissolution dans les systèmes, 3éme Colloque d'Hydrologie en Pays Calcaires, Besançon. 147-157.

Lepiller, M., Mondain, P.-H. and Cardin, P., 1988. Les recherches en hydrogéologie karstique menées depuis dix ans dans les massifs subalpins septentrionaux par le Laboratoire d'Hydrogéologie de l'Université d'Orléans (France). Bull. Centre Hydrogéol. Neuchâtel, 8, 27-48.

Maillet, E., 1905. Essais d'hydraulique souterraine et fluviale. Librairie Sci. A. Hermann, Paris, France. 218pp.

Mandelbrot, B.B., 2000. Fractales, hasard et finance. Flammarion, Paris, France.

Mandelbrot, B.B., 2001. Gaussian self-affinity and fractals. Ed. Springer, Berlin, Germany. 654pp.

Mandelbrot, B.B. and Wallis, J.R., 1968. Noah, Joseph and operational hydrology. Water Resour. Res., 4, 909-918.
Mandelbrot, B.B. and Wallis, J.R., 1969. Computer experiments with fractional Gaussian noises, Part 1, 2 and 3,. Water Resour. Res., 5, 228-267.

Mangin, A., 1970. Contribution à l'étude d'aquifères karstiques à partir de l'analyse de courbes de décrues et de tarissement. Ann. Spéléologie, 25, 581-609.

Mangin, A., 1975. Contribution à l'étude hydrodynamique des aquifères karstiques III. Thèse de doctorat en Sciences Naturelles, Dijon. Ann. Spéléologie, 30, 21-24.

Mangin, A., 1981. Utilisation des analyses corrélatoires et spectrales dans l'approche des systèmes karstiques. C. R. Acad. Sci. Paris, 293, 401-404.

Mangin, A., 1982. L'approche systémique du karst, conséquences conceptuelles et méthodologiques. Reunion monografica sobre el karst, Larra. 141-157.

Mangin, A., 1984. Pour une meilleure connaissance des systèmes hydrologiques à partir des analyses corrélatoires et spectrales. J. Hydrol., 67, 25-43.

Mangin, A., 1994. Karst hydrogeology. Groundwater Ecology. Academic Press, Orlando, Florida,USA. 43-67

Marsaud, B., 1996. Structure et fonctionnement de la zone noyée des karsts à partir de résultats expérimentaux. Ph.D. Thesis, Paris XI, Orsay, France.

Mathevet, T., 2002. Analyse du fonctionnement du système karstique de Bange-L'Eau-Morte (Bauges, Savoie \& HauteSavoie, France). Unpublished report of M. Sc. Thesis (DEA HHGG), Ecole supérieure des Mines de Paris, Paris, France.

Max, J., 1980. Méthodes et techniques du traitement du signal et applications aux mesures physiques. Masson, Paris, France. 379pp.

Mondain, P.H., 1991. Hydrogéologie des systèmes karstiques de l'unité delphino-helvétique inférieure entre les vallées du Fier et du Borne (Massif des Bornes, Haute-Savoie, France). Ph.D. Thesis, Université d'Orléans, France. 561pp.

Morales Juberias, T., Cruz Sanjulian, J., Zafra, P., Olazar, M. and Arandes, J.M., 1996. Study of natrual responses of Olalde karst system (Basque country) : analysis of its internat structure. Hydrogéologie, 1, 39-52.

Muet, P., 1989. Hydrogéologie du nord-est du Causse de Martel (Corrèze). Hydrogéologie, 1, 27-44.

Nakken, M., 1999. Wavelet analysis of rainfall-runoff variability isolating climatic from anthropogenic patterns. Environ. Model S., 14, 283-295.

Padilla, A. and Pulido Bosch, A., 1995. Study of hydrographs of karstic aquifers by means of correlation and cross-spectral analysis. J. Hydrol., 168, 73-89.

Pulido Bosch, A., de Marsily, G. and Benavente, J., 1987. Analisis de la descarga del Torcal. Hidrogeología, 2, 17-28.

Smith, L.C., Turcotte, D.L. and B.L., I., 1998. Stream flow characterisation and features detection using a discrete wavelet transform. Hydrol. Process., 12, 30-56.

Torrence, C. \& Compo, G.P., 1998. A practical guide to wavelet analysis. Bull. Amer. Meteorol. Soc., 79, 61-78.

Walliser, B., 1977. Systèmes et modèles. Seuil, Paris, France.

Yevjevitch, V., 1972. Stochastic process in hydrology. Water Resources Publication, Fort Collins, Colorado, USA. 276pp. 